\title{
Simvastatin reduced mortality and vascular events in diabetes mellitus
}

Collins R, Armitage J, Parish S, et al. MRC/BHF Heart Protection Study of cholesterol-lowering with simvastatin in 5963 people with diabetes: a randomised placebo-controlled trial. Lancet 2003;361:2005-16.

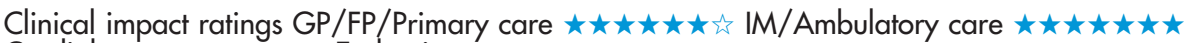

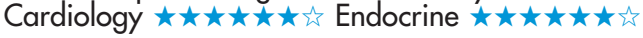

\section{In patients with diabetes mellitus, does simvastatin reduce vascular events?}

\section{METHODS}

Design: randomised placebo controlled trial.
Allocation: \{concealed*\}t.
Blinding: blinded \{participants, clinicians, data collectors, and
outcome assessors\}t.

\section{MAIN RESULTS}

Analysis was by intention to treat. Patients in the simvastatin group had fewer coronary events, strokes, revascularisation procedures, and major vascular events (table).

\section{CONCLUSION}

In adults with diabetes mellitus, simvastatin therapy at $40 \mathrm{mg}$ daily reduced vascular events.

\section{Abstract and commentary also appear in ACP Journal Club.}

For correspondence: Heart Protection Study, Raddliffe Infirmary, Oxford, UKK. hps@ctsu.ox.ac.uk

Sources of funding: UK Medical Research Council; British Heart Foundation; Merck \& Co; Roche Vitamins Ltd.

\section{Commentary}

$\square$ eart Protection Study (HPS) participants were selected for having a high risk of cardiovascular disease, not for having high low density lipoprotein (LDL) cholesterol concentrations. 2463 of the 5963 participants who had diabetes also had a history of vascular disease at baseline; 2426 had pretreatment LDL concentrations $<3.0 \mathrm{mmol} / \mathrm{l}$. The most important result was that a standard $40 \mathrm{mg}$ daily of simvastatin (not treatment to target cholesterol concentrations) reduced LDL levels by about $1 \mathrm{mmol} / \mathrm{l}$ on average, and reduced major cardiovascular events by $22 \%$ in all diabetic participants. In an extensive subgroup analysis, treatment benefit differed little across age, sex, type of diabetes, duration of diabetes, degree of glucose control, baseline cholesterol concentration, or presence of known vascular disease.

The study by Collins et al adds weight to the mounting evidence that treating diabetes with a statin can reduce the risk of major cardiovascular events, even though the most common lipid abnormality in diabetes is a combination of low high density lipoprotein (HDL) and high triglyceride concentrations (a marker for small dense LDL concentrations often observed without high cholesterol concentrations). The results for cholesterol lowering are more impressive and more consistent than the results for treating hyperglycaemia, and highlight the need to do both when managing patients with diabetes.

This landmark study provides abundant evidence that diabetes is a heart disease equivalent in terms of future cardiovascular risk. It is now clear that lowering any concentration of total cholesterol or LDL cholesterol should be attempted in all patients with diabetes. In fact, one could question the need to measure cholesterol at all, although most physicians will feel more comfortable knowing where they started, and many patients will be motivated to continue medication if they can see their cholesterol concentrations fall. Another reason to measure lipid concentrations (including non-fasting triglyceride concentrations) is to identify patients with particularly high triglyceride or low HDL concentrations for special therapy. Total, LDL, and HDL cholesterol concentrations do not need to be measured in fasting patients, which makes test results easier to monitor.

This well done and well analyzed trial solidifies the evidence for treating almost all diabetic patients with statins, and has already sparked considerable discussion about the need for cholesterol measurement, treatment targets, and combination therapies. The HPS results do not address whether additional lipid-lowering treatment for the common combination of high triglyceride and low HDL concentrations provides added cardiovascular benefit relative to costs and risks.

Elizabeth Barrett-Connor, MD University of California, San Diego La Jolla, California, USA

Simvastatin (Sim) $v$ placebo in diabetes mellitus at mean 4.8 year follow up*

\begin{tabular}{|c|c|c|c|c|}
\hline Outcomes & Sim & Placebo & $\operatorname{RRR}(95 \% \mathrm{Cl})$ & NNT (Cl) \\
\hline $\begin{array}{l}\text { Major coronary } \\
\text { eventt }\end{array}$ & $9.4 \%$ & 13 & 6) & 60) \\
\hline Stroke & $5.0 \%$ & 6. & $23 \%$ & 69138 \\
\hline Revascularisation & $8.7 \%$ & $10 \%$ & to 28 ) & 62 (32 to 770 ) \\
\hline $\begin{array}{l}\text { Major vascular } \\
\text { eventł }\end{array}$ & $20 \%$ & $25 \%$ & $19 \%$ (11 to 27$)$ & 21 (15 to 37 ) \\
\hline
\end{tabular}

*Abbreviations defined in glossary; RRR, NNT, and Cl calculated from data in article.

†Myocardial infarction or coronary death.

$\ddagger$ Major coronary events, strokes, and revascularizations. 